\title{
Direct upstream integration of biogasoline production into current light straight run naphtha petrorefinery processes
}

\author{
Aron Deneyer ${ }^{(1)}$, Elise Peeters ${ }^{\circledR}{ }^{1}$, Tom Renders ${ }^{\circledR}{ }^{1}$, Sander Van den Bosch ${ }^{\circledR}{ }^{1}$, Nette Van Oeckel', \\ Thijs Ennaert', Tibor Szarvas ${ }^{2}$, Tamás I. Korányi $\mathbb{1}^{2}{ }^{2}$, Michiel Dusselier ${ }^{1 \star}$ and Bert F. Sels ${ }^{1 \star}$
}

There is an urgent need to address environmental problems caused by our transportation systems, which include the reduction of associated $\mathrm{CO}_{2}$ emissions. In the short term, renewable drop-in fuels are ideal, as they allow a direct integration into the existing infrastructure. However, preferably they would perform better than current alternatives (for example, bioethanol) and be synthesized in a more efficient way. Here we demonstrate the production of biogasoline with a direct upstream integration into processes in existing petrorefinery facilities that targets the $10 \%$ bio-based carbon in accordance with the current European Union directives (for 2020) for biofuels. To achieve this goal, we show the valorization of (hemi)cellulose pulp into light naphtha using a two-phase $\left(\mathrm{H}_{2} \mathrm{O}\right.$ :organic) catalytic slurry process. $A \mathrm{C}_{5}-\mathrm{C}_{6}$ alkane stream, enriched with bio-derived carbon and compatible with further downstream petrorefinery operations for (bio)gasoline production, is automatically obtained by utilizing fossil light straight run naphtha as the organic phase. The ease of integration pleads for a joint petro/bio effort to gradually produce bio-enriched gasolines, wherein the chemical compounds of the bio-derived fraction are indistinguishable from those in current high-quality gasoline compositions.

A growing body of literature recognizes the importance of a sustainable production of fuel (additives) ${ }^{1-3}$, chemicals and materials $^{4}$ from abundant and renewable lignocellulose $e^{5,6}$. Despite lignocellulose's high degree of functionality ${ }^{7}$, its conversion into alkanes can become an important alternative for bio-enrichment or the replacement of fossil-based alkanes ${ }^{8}$. The synthesis of identical molecules from an alternative biomass feedstock, instead of from crude oil, encompasses a promising strategy for the integration of bio-based carbon in the short term ${ }^{9}$. Integration of these technologies in an existing petrorefinery is, perhaps, the most straightforward and efficient way to proceed, but such synergies are currently immature.

In line with rising concerns about fossil-derived $\mathrm{CO}_{2}$ and climate change, objectives related to the implementation of renewable energy, including biofuels, have been put forward (Supplementary Note 1$)^{10}$. The dependency of our current transportation market on diesel $\left(\mathrm{C}_{10}-\mathrm{C}_{22}\right)$, kerosene $\left(\mathrm{C}_{8}-\mathrm{C}_{16}\right)$ and gasoline $\left(\mathrm{C}_{5}-\mathrm{C}_{12}\right)$, certainly in the short-to-mid term, will still be high ${ }^{11}$. Therefore, the European Union for one, has targeted a market share of $10 \%$ for biofuels in transportation by $2020^{12}$, with a maximum of $7 \%$ from first-generation biomass ${ }^{10}$. Introducing renewable diesel as a dropin fuel, for instance, by Neste Oil, is one example to achieve these objectives. Nevertheless, the consumption of diesel, in contrast to that of gasoline, leads to a higher emission of particulate matter and $\mathrm{NO}_{\mathrm{x}}$ (for example, diesel exhaust emission scandals), a problem not solved by biodiesel replacement. Therefore, the importance of light fuels, such as gasoline, whether or not as an energy carrier in a future hybrid engine, will probably increase. Currently, gasoline, which is synthesized by blending different petrorefinery streams (for example, alkylate, isomerate and reformate) and light distillate feedstock, has an annual consumption of approximately $32 \mathrm{vol} \%$ of the global oil market, which corresponds to more than 1,350 (or 4,200 for the total oil market) million metric tonnes yearly ${ }^{13}$.

Blending bio-based ethanol with fossil gasoline is today's most widely used option, and therefore, most objectives are expressed in $\mathrm{E}$ values (\% ethanol in fuel blends, for instance E10 in several European countries). The implementation of ethanol, synthesized through an already well-developed technology, leads to lower $\mathrm{CO}_{2}$ emissions and a higher combustion quality because of ethanol's high octane number (the research octane number is 130 (ref. $\left.{ }^{14}\right)$ ). Although bioethanol is on the rise, its blending into gasoline also encompasses some drawbacks and limitations: the direct loss of two carbons in form of $\mathrm{CO}_{2}$ per $\mathrm{C}_{6}$-hexose during the production of ethanol ${ }^{7}$, a lower energy density compared to that of conventional gasoline (so a lower vehicle distance range ${ }^{15}$ and an ongoing debate about the compatibility with traditional vehicle materials ${ }^{15}$. Moreover, the current fermentative ethanol production mainly consumes edible carbohydrate resources (for example, corn and sugarcane). This is a consequence of the complexity of cellulose conversion, which leads to an approximately three times higher investment cost for a second-generation plant in comparison with a first-generation plant ${ }^{10}$.

Besides bioethanol, myriads of emerging technologies to transform lignocellulose into alkanes have been reported, which encompass thermochemical and mild catalytic approaches. Gasification ${ }^{16,17}$ and pyrolysis/liquefication ${ }^{18-20}$ are the most promising thermochemical technologies. These methods generally yield a broad product distribution (namely, an enormous diversity of liquid hydrocarbons as well as gases and solid biochar), which may complicate the introduction in operational petrorefinery facilities because of serious risks (for example, the necessity to modify the traditional petrorefinery at different levels). Moreover, the valorization towards light 


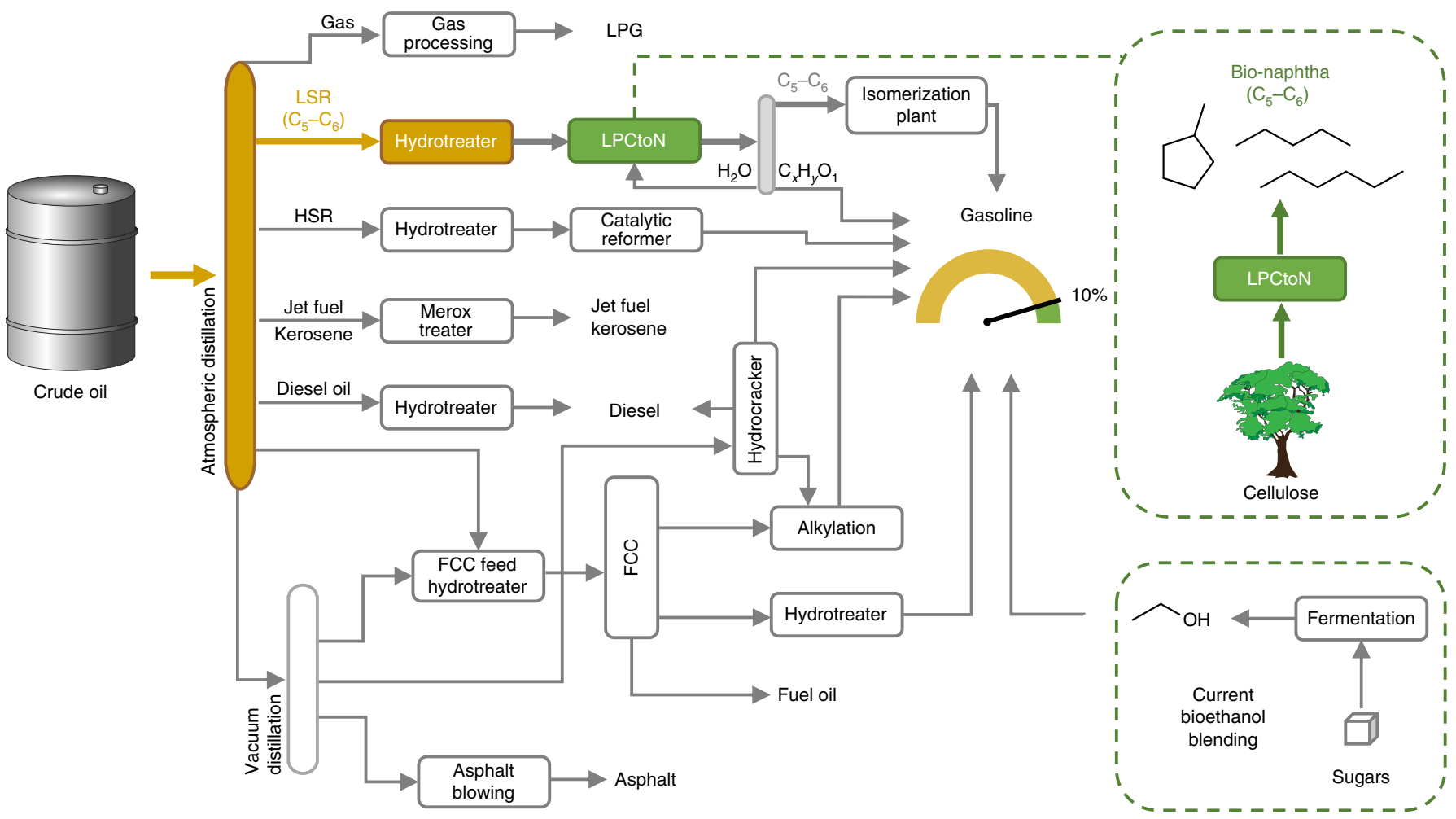

Fig. 1 | Schematic representation of a petrorefinery with upstream integration of the LPCtoN technology. LPCtoN enriches a petrochemical stream (gold) with renewable bio-naphtha $\left(\mathrm{C}_{5}-\mathrm{C}_{6}\right.$ (green), and thus chemically identical molecules) before its processing in an existing LSR isomerization unit of the petrorefinery. In line with European Union directives, an integration of 10\% bio-derived carbon in transportation fuels by 2020 is the aim. Current bioenrichment is done by ethanol blending downstream (below right). LSR, light straight run naphtha; HSR, heavy straight run naphtha; FCC, fluid catalytic cracking; LPG, liquid petroleum gas; LPCtoN, liquid phase cellulose-to-naphtha.

biofuels (gasoline) is rather limited, for instance, obtaining mainly heavy fractions from the Fischer-Tropsch synthesis using biomassderived syngas or from typical liquefaction processes ${ }^{20,21}$.

Here we demonstrate an alternative catalytic approach at lower temperature that converts (hemi)cellulosic pulp into light naphtha in a two-phase catalytic slurry process. The typical $\mathrm{C}_{5}-\mathrm{C}_{6}$ cut from a petrorefinery is ideal as the organic phase (solvent), in addition to its high stability, and alkanes therein are capable of dissolving substantial amounts of water at elevated temperatures, which improves its extraction ability for intermediate furanics in the chemical process. The integration of such a petrorefinery stream enables its immediate and controlled enrichment with bio-carbon in a single step, validated by ${ }^{14} \mathrm{C}$-isotope measurements. The hydrogen-rich light naphtha stream is easily fed into a classic petrorefinery hydro-isomerization unit to produce a bio-enriched isomerate with improved octane properties.

\section{Integration in the petrorefinery}

Mild catalytic approaches, which require fractionated (and purified) cellulosic substrates, enable the preservation of the native carbon skeleton and thus a high $\mathrm{C}_{5}-\mathrm{C}_{6}$ product selectivity from the carbohydrate streams ${ }^{22-25}$. Such a $\mathrm{C}_{5}-\mathrm{C}_{6}$ alkane cut resembles the so-called light straight run naphtha (LSR) in petrorefineries, which is typically isomerized into branched alkanes to increase the gasoline octane number, from below 70 to above 90, before its blending into gasoline. The need for this light isomerization unit is gaining importance because of the restrictions on sulfur, olefin and aromatic content in gasoline ${ }^{13,26}$. At the same time, the processed quantity of these light isomerization units is diminishing because heavier crude oils are becoming relatively more important ${ }^{13}$. Therefore, this contribution proposes the use of larger quantities of light naphtha streams, enriched from a bio-source, in gasoline blends. The strategy, presented in Fig. 1, envisions, in contrast to current state-ofthe-art procedures, the direct bio-enrichment of the present LSR streams by converting (ligno)cellulosic feedstock in a biphasic slurry process into light bio-naphtha in the presence of deep hydrodeoxygenation (HDO) catalysts with LSR as the organic phase. In line with traditional petrorefinery operations, the preferred LSR streams undergo hydrotreatment to prevent catalyst deactivation and are thus sulfur free prior to the enrichment ${ }^{27,28}$. The subsequent hydro-isomerization unit converts the total LSR stream into a highquality bio-enriched isomerate for gasoline blends. The literature shows that the choice of catalyst (for example, chlorinated alumina, sulfated zirconia or zeolites) in the isomerization unit is crucial, and this is determined by the catalyst lifetime and the tolerance against $\mathrm{S}$-, $\mathrm{N}$ - and $\mathrm{O}$-containing compounds and $\mathrm{H}_{2} \mathrm{O}$, as well as the operating process window of the existing facility ${ }^{26,29,30}$. For instance, Pt-loaded zeolites need to work at higher temperature, which shifts the thermodynamic equilibrium in a negative way (to less-branched isomers), but they have a higher tolerance regarding impurities such as $\mathrm{H}_{2} \mathrm{O}$ and oxygenates ${ }^{26}$, and are therefore preferred here. Optionally, oxygenates (for example, 2,5-dimethyltetrahydrofuran with a research octane number of $82\left(\right.$ ref. $\left.{ }^{14}\right)$ ) may be removed by distillation prior to isomerization, and then added back into the gasoline blend as valuable substitutes for their superior properties, such as their higher energy density than ethanol ${ }^{15}$.

The scalability of the proposed bio-integration in the petrorefinery is motivated by detailed calculations in Supplementary Note 2 and Supplementary Figs. 1 and 2. In general, a petrorefinery plant processes approximately 20 million metric tonnes of crude 


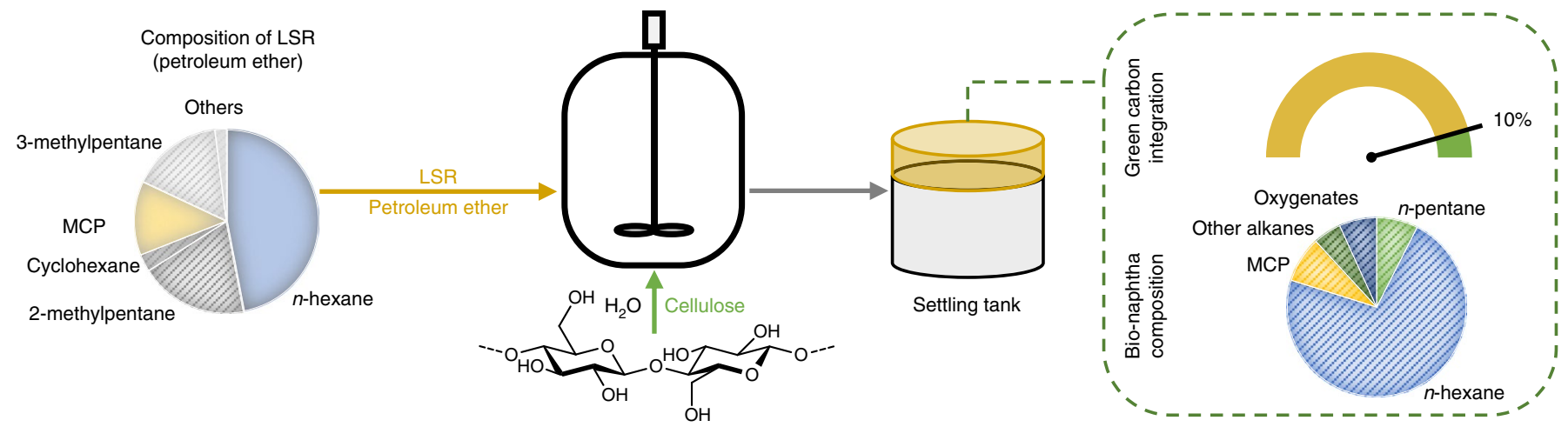

Fig. 2 | Direct enrichment of fossil-derived LSR (petroleum ether) with bio-naphtha via the LPCtoN process. Conditions: $2 \mathrm{~g}$ Vivapur cellulose, $4.8 \mathrm{~g}$ $\mathrm{H}_{4} \mathrm{SiW}_{12} \mathrm{O}_{40}, 0.25 \mathrm{~g} \mathrm{Ru} / \mathrm{C}$; biphasic system ( $\left.40 \mathrm{ml}\right), \mathrm{H}_{2} \mathrm{O}$ /petroleum ether (75:25), $5 \mathrm{MPa} \mathrm{H}_{2}$ at room temperature (r.t.); temperature programme from r.t. to $423 \mathrm{~K}\left( \pm 12 \mathrm{~K} \mathrm{~min}^{-1}\right)$ and from $423 \mathrm{~K}$ to $493 \mathrm{~K}\left( \pm 0.5 \mathrm{~K} \mathrm{~min}^{-1}\right)$; total reaction time of $5 \mathrm{~h}$. Other alkanes (LPCtoN): $n$-butane, 2 -methylpentane, 3-methylpentane. Oxygenates: $\mathrm{C}_{x} \mathrm{H}_{y} \mathrm{O}_{1}$ present in the organic phase. MCP, methylcyclopentane.

oil annually ${ }^{13}$, of which 5-15 vol\% (depending on the oil feedstock) ends up in LSR ${ }^{31}$. Enrichment of the fossil LSR with, for instance, $10 \%$ bio-based carbon from lignocellulose carbohydrate streams therefore requires an annual processing of approximately one million metric tonnes of lignocellulose. This capacity, which is the typically applied feedstock volume in the pulp and paper industry (for example, a large-sized paper-mill), thus indicates its feasibility in terms of logistics, sustainability and so on.

\section{Direct bio-based carbon enrichment of fossil light naphtha}

The liquid phase cellulose-to-naphtha (LPCtoN) technology we have designed comprises a biphasic catalytic system that consists of a reactive aqueous phase with a soluble heteropolyacid, and a reactive organic phase with polyacid-modified ruthenium on carbon, executed in a stirred slurry reactor. Heteropolyacids were chosen because of their high solubility in polar solvents, strong acidity and interaction with carbohydrates, which enable fast hydrolysis and dehydration, high affinity for adsorption on carbon and non-volatile character, which avoid downstream product contamination ${ }^{32,33}$. For the heterogeneous redox catalyst, smooth metal surfaces of, for instance, $\mathrm{Ru}$ are required to facilitate 5-hydroxymethylfurfural (5-HMF) hydrogenation. The hydrophobic carbon support adsorbs part of the heteropolyacid and compartmentalizes this bifunctional acid-metal catalyst in the organic phase, where it selectively executes dehydration/hydrogenation cycles with a minimum carbon-carbon bond dissociation. In this way, the direct conversion of cellulose into light naphtha, in the order of 300 kilograms of cellulose per day per cubic metre of reactive phase, can be achieved at mild temperatures $(493 \mathrm{~K})$ under $\mathrm{a} \mathrm{H}_{2}$ atmosphere $(5 \mathrm{MPa})$. Although this value is non-optimized and may probably be improved further, it already surpasses that of more mature bioethanol fermentation processes, which show about 50 kilograms of sugar conversion per day per cubic metre ${ }^{34}$

Few liquid-phase cellulose-to-alkane conversions in biphasic catalytic conditions are reported ${ }^{22,23}$. The chemistry related to these HDO strategies is discussed in Supplementary Note 3 with the reaction paths in Supplementary Fig. 3. Accordingly, we studied cellulose-to-alkane conversions in a fossil naphtha/ $\mathrm{H}_{2} \mathrm{O}$ system in the presence of the aforementioned polyacid and modified $\mathrm{Ru}$ on carbon catalyst, but used petrol and petroleum ether (instead of the commonly used (do)decane solvent). Petrol, with a boiling point between 363 and $373 \mathrm{~K}$, mainly contains $\mathrm{C}_{7}$ alkanes (99\%), of which $43 \%$ are linear, $29 \%$ branched and $27 \%$ cyclic. Petroleum ether is a lighter fraction with a boiling point between 333 and $353 \mathrm{~K}$, and mainly contains $\mathrm{C}_{6}$ alkanes (98\%), of which $47 \%$ are linear, $35 \%$ branched and $16 \%$ cyclic. Particularly the latter solvent resembles the $\mathrm{C}_{6}$ composition of a typical LSR before isomerization ${ }^{35}$. The use of petroleum ether and petrol as the organic solvents was investigated in the biphasic slurry reactor first using a naphtha/ $\mathrm{H}_{2} \mathrm{O}$ (25:75) mixture that contained $7 \mathrm{wt} \%$ cellulose in water. Complete cellulose conversion was achieved with a cellulose-to-alkane efficiency of $76 \mathrm{~mol} \% \mathrm{C}$ and $68 \mathrm{~mol} \% \mathrm{C}$ for petroleum ether (Fig. 2) and petrol, respectively (measured in the organic phase). The distribution within the bio-based products is approximately equal for both fractions: $70 \% n$-hexane, $10 \%$ methylcyclopentane, $9 \% n$-pentane, $4 \%$ other $\mathrm{C}_{4-6}$ alkanes and $7 \%$ oxygenates (which consist of tetrahydrofuran, pyran and oxepane-related $\mathrm{C}_{5-6}$ structures, as well as $\mathrm{C}_{5-6}$ mono-alcohols). Thus, cellulose can be converted in both LSR model solvents, but a significant difference in carbon efficiency was observed.

Solubility is key in the biphasic cellulose-to-alkane process. It is desirable that cellulose hydrolysis and sugar dehydration (for example, to 5-HMF) are carried out in the water phase, whereas further hydrogenation and conversion via dehydration-hydrogenation to alkanes should occur in the organic phase. The catalyst properties play a crucial role in this dual compartmentalization strategy, as discussed in Supplementary Note 4, Supplementary Figs. 4 and 5 and Supplementary Table 1. It is essential that the metal is loaded on a hydrophobic support to keep metal redox activity exclusively in the organic phase, the support is able to adsorb and extract part of the acidity in the organic phase to ensure its bifunctional catalytic property (heteropolyacids and carbon are good partners ${ }^{36}$ ) and, in the case of $\mathrm{Ru}$, large particle sizes are used to favour aromatics hydrogenation.

Besides the catalytic properties, the solvent choice is of utmost importance to achieve the highest $\mathrm{C}$ efficiency, as we observed. Alkanes are the best choice in terms of stability regarding HDO. The solvent extractability, though, looks insufficient, especially for the early dehydrated intermediates such as 5-HMF. Dumesic et al. were first to demonstrate the usefulness of a biphasic solvent system for hydroxymethylfurfural (HMF) production from fructose ${ }^{14,37,38}$. The extraction-stabilization trends for the production of HMF are highlighted in a recent review ${ }^{39}$. To our knowledge, the use of alkanes, explicitly in our interest for the integration, has not been reported, obviously because of the very low extraction capacity of alkanes for $\mathrm{HMF}$ at a moderate reaction temperature.

Notably, use of high temperature $(>500 \mathrm{~K})$ shows a different solvation behaviour. The thermodynamics of the water-alkane mutual solubility at such circumstances have been reported ${ }^{40-43}$. Under our reaction conditions, namely, up to $493 \mathrm{~K}$, the biphasic alkane-water solvent system behaves like a three-phase system in which the gas composition is in equilibrium with two liquid phases, one water rich 


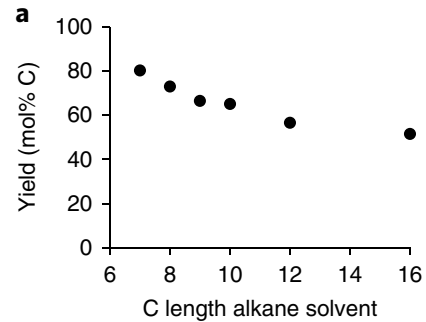

b

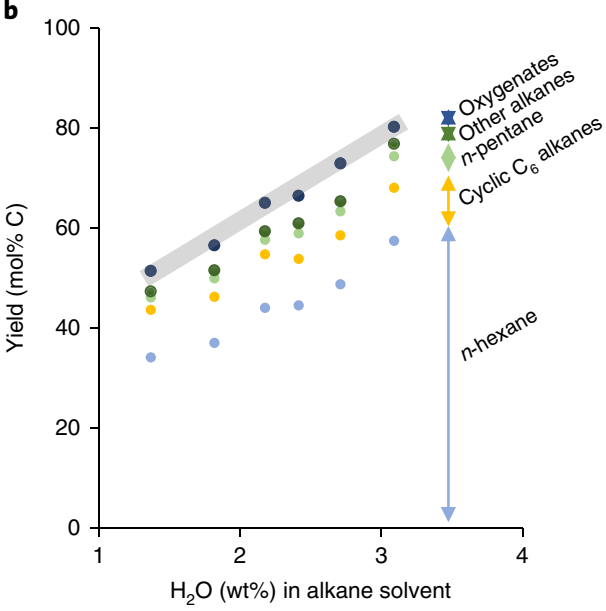

c

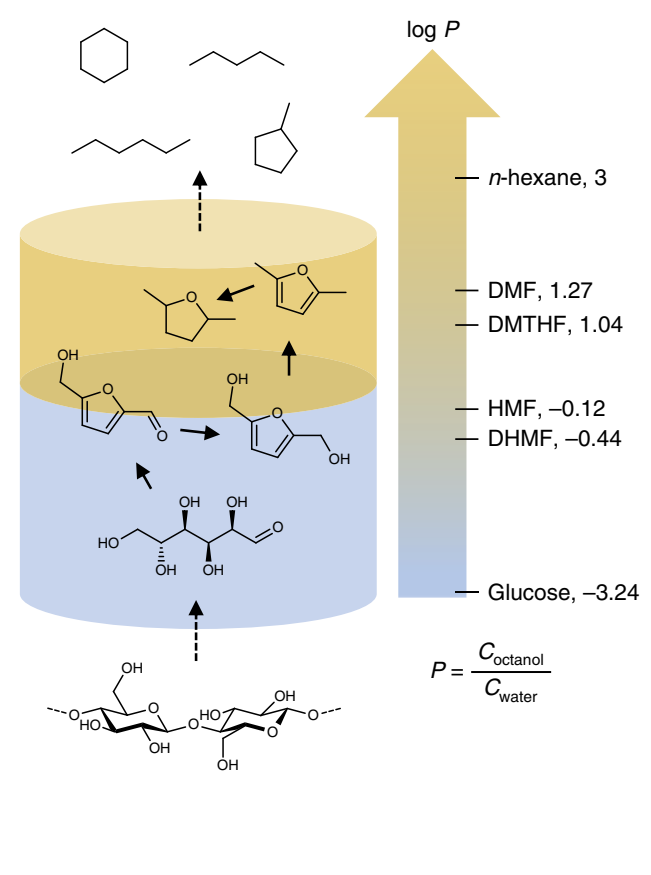

Fig. 3 Influence of the alkane solvent on the biphasic LPCtoN technology. a, Representation of the LPCtoN efficiency using different linear alkanes as the solvent, ranging from $n$-heptane $\left(C_{7}\right.$, octane number 0$)$ to $n$-hexadecane $\left(C_{16}\right) . \mathbf{b}$, Cumulative representation of the individual product yields as well as the total yield as a function of wt $\% \mathrm{H}_{2} \mathrm{O}$ in the alkane solvent. The wt $\% \mathrm{H}_{2} \mathrm{O}$ in each alkane solvent is estimated via the mutual solubility data of normal alkanes and $\mathrm{H}_{2} \mathrm{O}$ at $493 \mathrm{~K}$. The shorter the alkane solvents, the higher the amount of $\mathrm{H}_{2} \mathrm{O}$ (on a weight basis) in the alkane solvent ${ }^{41-43}$. c, $\mathrm{LPCtoN}$ reaction scheme that highlights the intermediates with no pronounced preference for the $\mathrm{H}_{2} \mathrm{O}$ or organic phase. The polarity, determined by means of $\mathrm{ChemDraw}$ Ultra 12.0 software, is presented by $\log P$, which is the concentration $(C)$ of molecule $\mathrm{X}$ in octanol in relation to the concentration of molecule $\mathrm{X}$ in $\mathrm{H}_{2} \mathrm{O}$. A low $\log P$ corresponds to a high polarity, whereas a high log $P$ corresponds to a low polarity. Conditions: $2 \mathrm{~g}$ Vivapur cellulose, $4.8 \mathrm{~g} \mathrm{H}_{4} \mathrm{SiW}_{12} \mathrm{O}_{40}, 0.25 \mathrm{~g}$ $\mathrm{Ru} / \mathrm{C}$; biphasic system $(40 \mathrm{ml}), \mathrm{H}_{2} \mathrm{O} /$ alkane $(75: 25), 5 \mathrm{MPa} \mathrm{H}_{2}$ at r.t.; temperature programme from r.t. to $423 \mathrm{~K}\left( \pm 12 \mathrm{~K} \mathrm{~min}^{-1}\right)$ and from $423 \mathrm{~K}$ to $493 \mathrm{~K}$ $\left( \pm 0.5 \mathrm{~K} \mathrm{~min}^{-1}\right)$; total reaction time of $5 \mathrm{~h}$. DHMF, dihydroxymethylfurfural; DMTHF, dimethyltetrahydrofuran, DMF, dimethylfuran.

and the other alkane rich phase. The compositions of each phase can be estimated using the reported mutual solubility data of water and alkanes ${ }^{40-43}$. The solubility of alkanes in water, although higher at a higher temperature and higher for shorter carbon chain lengths, remains very low, namely, in the order of $1-1,000 \mathrm{ppm}$. Any solvent effect in the water phase from such low solute molarities on catalysis (in terms of partition, $\mathrm{pH}$ or $\mathrm{H}_{2}$ solubility) can probably be discarded. However, the solubility of water in alkanes at an elevated temperature is surprisingly high, reaching values up to around $50 \%$ mole fraction at $513 \mathrm{~K}$. As this mole fraction only differs slightly with the carbon number of the alkane, short alkanes at a high temperature contain higher weight amounts of water than long alkanes. We hypothesize, therefore, that the extraction of intermediate oxygenates (needed for their further conversion into alkanes in the LSR phase) likewise becomes sufficiently high in the aqueous alkane phase at the elevated temperature and is especially favourable for the shorter-chain alkanes.

To substantiate this hypothesis, we performed the biphasic cellulose-to-alkane catalytic system using alkane solvents with a varying carbon number (Fig. 3a) (and skeleton (Supplementary Table 2)). The results show a substantial increase in $\mathrm{C}$ yield with decreasing carbon number of the alkane solvent, ranging from $52 \mathrm{~mol} \% \mathrm{C}$ (for $n$-hexadecane) to $81 \mathrm{~mol} \% \mathrm{C}$ (for $n$-heptane). This trend correlates well with the aforementioned calculated water solubility (Fig. 3b). In fact, one can also assume a higher polarity of the short alkane solvents as they allow a higher uptake of water per volume. Estimations of the partition coefficient of the alkanes in water-octanol (as $\log \mathrm{P}$ (Supplementary Fig. 6)) subscribe the polarity differences with the carbon chain length. The polarity values (as $\log P$ ) of the reaction intermediates involved in the cellulose-to-alkane conversion are illustrated in Fig. 3c.

Taken together, short alkanes lead to a relatively polar organic phase, which in turn favours the solvent interaction with water and the intermediates (for example, $\mathrm{HMF}$ ). $\mathrm{C}_{5}-\mathrm{C}_{6}$-containing light naphtha streams are therefore ideally suited for the anticipated cellulose-to-alkane conversion and afford high $\mathrm{C}$ yields.

\section{Towards a targeted bio-enrichment}

The LPCtoN technology is highly flexible in terms of bio-enrichment of the produced LSR fraction. Two process parameters can be adapted to target a specified enrichment: the ratio of the organic to water phase, and the loading of cellulose.

First, we note that the amount of water strongly affects the maximum alkane yield, and this value depends on the choice of the organic phase. This is illustrated, for instance, for $n$-heptane and $n$-hexadecane in Fig. 4a (and Supplementary Fig. 7). The results show that the use of $n$-heptane leads to an $81 \%$ maximum $C$ yield at a 75:25 water-to-alkane volume ratio, and the same exercise with $n$-hexadecane gives a $68 \%$ maximum $C$ yield at a 50:50 volume ratio. Remarkably, the absolute mass of water present in the alkane solvent, which is estimated from mutual solubility data ${ }^{41-43}$, is equal for $n$-heptane and $n$-hexadecane at their maximum LPCtoN yield (Supplementary Fig. 8). The plot demonstrates that, even after optimizing the water-to-alkane ratio for each solvent, light alkanes remain the preferred organic solvent for the LPCtoN technology. As a reference, an experiment without the additional organic phase produces only a $41 \%$ alkanes $C$ yield. 

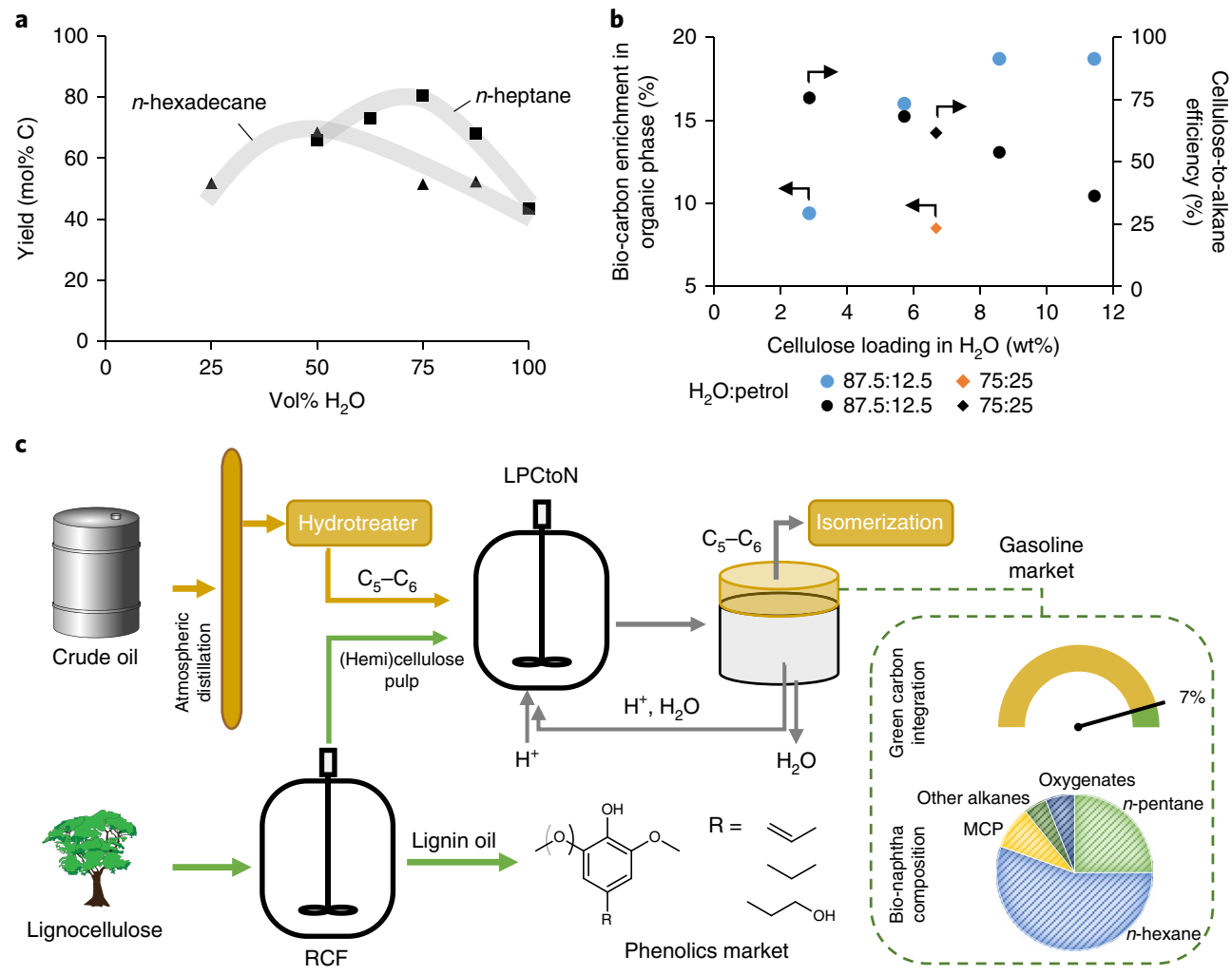

Fig. 4 | Influence of process variables and lignocellulose processing on the LPCtoN efficiency. a, The light naphtha yield for different $\mathrm{H}_{2} \mathrm{O}$ :alkane solvent ratios. b. Bio-carbon enrichment in petrol as well as the cellulose-to-alkane efficiency (at the same catalyst loading) for different cellulose loadings (wt\% in $\mathrm{H}_{2} \mathrm{O}$ ). c, Schematic representation of RCF of woody resources (here, birch sawdust) as the fractionation tool for the production of lignin-derived phenolics and a carbohydrate-enriched pulp (that is, a substrate for $\mathrm{LPCtoN}$ ). Conditions for RCF: $2 \mathrm{~g}$ birch sawdust, $0.2 \mathrm{~g} \mathrm{Ni}-\mathrm{Al}_{2} \mathrm{O}_{3}$ catalyst pellets, $40 \mathrm{ml}$ methanol, $3 \mathrm{MPa} \mathrm{H}_{2}$ at r.t.; temperature programme: from r.t. to $523 \mathrm{~K}\left( \pm 10 \mathrm{~K} \mathrm{~min}^{-1}\right)$; total reaction time of $3 \mathrm{~h}$. Conditions for LPCtoN: $2 \mathrm{~g}$ carbohydrate pulp (mixture of pulps obtained after two identical RCF reactions on $2 \mathrm{~g}$ birch sawdust) for $\mathbf{c}$ or $2 \mathrm{~g}$ Vivapur cellulose for $\mathbf{a} ; 4.8 \mathrm{~g} \mathrm{H}_{4} \mathrm{SiW}_{12} \mathrm{O}_{40}, 0.25 \mathrm{~g} \mathrm{Ru} / \mathrm{C}$; biphasic system $(40 \mathrm{ml}), \mathrm{H}_{2} \mathrm{O} /$ alkane $(75: 25 \mathrm{for} \mathbf{c}), 5 \mathrm{MPa} \mathrm{H}_{2}$ at r.t.; temperature programme: r.t. to $423 \mathrm{~K}\left( \pm 12 \mathrm{~K} \mathrm{~min}^{-1}\right)$ and from $423 \mathrm{~K}$ to $493 \mathrm{~K}\left( \pm 0.5 \mathrm{~K} \mathrm{~min}{ }^{-1}\right)$; total reaction time of $5 \mathrm{~h}$. Other alkanes: $\mathrm{n}$-butane, 2-methylpentane, 3-methylpentane. Oxygenates: $\mathrm{C}_{x} \mathrm{H}_{y} \mathrm{O}_{1}$ present in the organic phase.

Not only is the yield of the $\mathrm{C}_{5}-\mathrm{C}_{6}$ alkanes in $n$-heptane higher, but also the bio-enrichment increases because less organic solvent volume was used for the same amount of converted cellulose. For instance, the enrichment in $n$-hexadecane is $4 \%$, whereas it is $10 \%$ in $n$-heptane in the solvent conditions of their respective highest alkane $\mathrm{C}$ yields. Similar enrichment levels were obtained with petrol (Fig. 4b), a model LSR organic solvent. Higher bio-carbon enrichment up to $16 \%$ can be achieved in petrol without significantly affecting the cellulose-to-alkane efficiency (around $75 \mathrm{~mol} \%$ C) by lowering the petrol volume from 25 to $12.5 \%$. The highest bio-enrichment $(20 \%)$ was achieved with the same solvent ratio using a cellulose loading of $9 \mathrm{wt} \%$, which corresponds to a productivity level of 360 kilograms of cellulose per day per cubic meter of reactive phase, at a somewhat lower alkane $\mathrm{C}$ yield (55\%). A further increase in cellulose loading $(>10 \mathrm{wt} \%)$ does not result in a higher bio-carbon enrichment due to a too low HDO efficiency. The negative impact of a higher cellulose loading in water is further corroborated by additional experiments, discussed in Supplementary Note 5 and Supplementary Table 3, which indicates enhanced degradation reactions when the water-soluble species (such as 5-HMF) are concentrated.

Although petroleum ether is the most reliable solvent mixture to mimic real LSR, the study in petroleum ether is complicated due to the coinciding alkane composition with the products formed. So far in petrol, the yield of bio-based alkanes was determined by neglecting the fossil naphtha alkanes from the solvent in the integrated gas chromatography-flame ionization detector (GC-FID) signals of the final alkane product mixture, but this methodology is unreliable for petroleum ether. Therefore, isotope ${ }^{14} \mathrm{C}$ measurements were used to monitor the carbon origin. This low abundance isotope is less stable than ${ }^{12} \mathrm{C}$ and ${ }^{13} \mathrm{C}$, and the moment a living organism dies, its ${ }^{14} \mathrm{C}$ level decreases faster in accordance with the half-life time (5,730 years); this explains the presence of ${ }^{14} \mathrm{C}$ isotopes in the biomass (for example, only several years old) and its absence in crude oil (millions of years old). The results of the ${ }^{14} \mathrm{C}$ isotope measurements are summarized in Table 1, and confirm the aforementioned bio-enrichment of the naphtha streams in petroleum ether (Table 1, entry 1) and petrol (entry 2).

\section{Conversion of real cellulosic biomass}

A smooth integration of the biorefining process in current petrorefinery schemes demands a complete valorization of every component of a lignocellulosic feedstock ${ }^{44}$. More specifically, a viable scheme should include valorization of lignin, the largest renewable source of aromatic ${ }^{5,45}$. Recently, the advent of lignin-first biomass fractionation was highlighted ${ }^{46}$, either through a depolymerization-stabilization ${ }^{47}$ strategy or by preservation of the original ether linkages to generate a separate delignified pulp and a useful lignin $\mathrm{oil}^{48}$. To demonstrate the cellulose-to-alkane conversion with real feedstock, birch wood was processed by reductive catalytic fractionation (RCF) to provide impure (hemi)cellulose pulp. RCF was conducted here with a Ni- $\mathrm{Al}_{2} \mathrm{O}_{3}$ pellet catalyst under a $\mathrm{H}_{2}$ atmosphere at $523 \mathrm{~K}$ using methanol ${ }^{49}$. After $3 \mathrm{~h}$, a delignification degree of $84 \%$ was obtained, which provided a solid carbohydrate pulp 


\begin{tabular}{|c|c|c|c|c|c|c|c|}
\hline \multirow[t]{2}{*}{ Entry } & \multirow[t]{2}{*}{ Substrate } & \multirow[t]{2}{*}{$\begin{array}{l}\text { Substrate loading in } \\
\text { water (wt\%) }\end{array}$} & \multirow[t]{2}{*}{ Fossil solvent } & \multirow[t]{2}{*}{ Naphtha: $\mathrm{H}_{2} \mathrm{O}$} & \multicolumn{2}{|c|}{$\begin{array}{l}\text { Biomass-derived } \\
\text { content (wt\%) }\end{array}$} & \multirow[t]{2}{*}{$\begin{array}{l}\text { Detailed } \\
\text { information }\end{array}$} \\
\hline & & & & & GC & $\operatorname{LSC}\left({ }^{14} \mathrm{C}\right)$ & \\
\hline 1 & Vivapur cellulose & 7 & Petroleum ether & $25: 75$ & 10.7 & 12.1 & Figure 2 \\
\hline 2 & Vivapur cellulose & 6 & Petrol & $12.5: 87.5$ & 15.6 & 18.0 & Figure $4 b$ \\
\hline $3^{\mathrm{a}}$ & Lignin-first carbohydrate pulp & 7 & Petrol & $25: 75$ & 6.6 & 11.8 & Figure $4 c$ \\
\hline
\end{tabular}

${ }^{a}$ Carbohydrate pulp, obtained after a RCF of a second-generation biomass (here, birch sawdust), is mainly composed of $\mathrm{C}_{6}$ sugars, but also $\mathrm{C}_{5}$ sugars, residual lignin and other impurities (Supplementary Fig. 9). This substrate composition (before LPCtoN) results, in contrast to pure cellulose as the substrate, in a larger biomass-derived content difference between the GC and LSC analysis, probably through the presence of additional soluble bio-organics.

with $83 \% \mathrm{C}_{5}$ and $93 \% \mathrm{C}_{6}$ sugar retention. Subsequently, the carbohydrate pulp was converted into alkanes, as described above, with petrol as the organic solvent (Fig. $4 \mathrm{c}$ and additional experiments in Supplementary Notes 6 and 7, Supplementary Figs. 9 and 10 and Supplementary Tables 4 and 5). The (hemi)cellulose-to-alkane efficiency of this reaction amounted to a $56 \mathrm{~mol} \% \mathrm{C}$ yield, which corresponds to a bio-based carbon enrichment of 7\%. Additional analysis of the bio-enriched LSR with ${ }^{1} \mathrm{H}-\mathrm{NMR}$ and ${ }^{13} \mathrm{C}-\mathrm{NMR}$ spectroscopy (Supplementary Fig. 11) confirmed the presence of mainly (fossil and bio-derived) alkanes and only minor amounts of sugar-derived oxygenates. Phenolics, which are detrimental when present in gasoline, and aromatics in general were not found using NMR analysis of the obtained raw bio-naphtha. Given that the content of these molecules needs to be as low as possible for gasoline applications, the selective removal of lignin during RCF highlights the value of this fractionation step before LPCtoN. Besides, the presence of hemicellulose in the carbohydrate pulp did not hamper the HDO process, and resulted in more $n$-pentane formation, which is also present in typical fossil LSR $\left(\mathrm{C}_{5}-\mathrm{C}_{6}\right)$ streams. The fibrous structure of the pulp after RCF, visualized by scanning electron microscopy (SEM) (Supplementary Fig. 12), and the high cellulose content substantially improve the cellulose-tohexane efficiency $(46 \mathrm{~mol} \% \mathrm{C})$, in line with previous insights that reported the beneficial effect of large cellulose particle sizes and/or fibres $^{50}$. The bio-carbon enrichment from this lignin-first carbohydrate pulp was confirmed via ${ }^{14} \mathrm{C}$ isotope measurement (Table 1 , entry 3). A successful integration of real lignocellulosic feedstock was thus realized, which yields valuable product streams for the chemical industry, namely, phenolics from lignin and bio-naphtha from the (hemi)cellulose pulp produced in only two catalytic steps. Although the valorization of sugar (streams) is well established in the current chemical industry (for example, bio-ethanol and paper), valorization of lignin towards phenolics is lacking at an industrial level. Today, lignin of a biorefinery, which is typically condensed/degraded, is burned for energy recuperation or used in low-value applications such as fillers. Nevertheless, recently developed lignin-first strategies are a stimulant to investigate new routes towards phenolics from native lignin with potentially high added value ${ }^{46}$. These phenolics can be immediately integrated in the current industrial market of phenolic resins. Moreover, different lignin-derived applications, that is, bulk chemicals, such as phenol $^{51}$ or new types of bisphenol polymers ${ }^{52,53}$, are reported at the academic level.

\section{Isomerization of bio-based carbon-enriched LSR}

As already mentioned, petroleum ether used here resembles the $\mathrm{C}_{6}$ part of LSR. In petrorefineries, LSR, obtained after the atmospheric distillation of crude oil, is typically hydrotreated (for example, for $\mathrm{S}$ removal) and isomerized to obtain a highly branched $\mathrm{C}_{5}-\mathrm{C}_{6}$ fraction. In addition, supplementary units can be integrated before and/ or after a typical naphtha isomerization, for instance a benzene satu- ration unit to decrease the aromatic content or de-isopentanizer/ isohexanizer to recover low-octane molecules for multiple isomerization runs. In the end, an upgraded $\mathrm{C}_{5}-\mathrm{C}_{6}$ fraction suitable for gasoline is obtained.

The bio-enrichment of LSR with $10 \%$ bio-based carbon (denoted as $\operatorname{LSR}(10 \%)$ (Figs. 2 and 5)), following our technology, results in an alkane composition of approximately $50 \% n$-hexane, and this fraction thus features a low octane number. Therefore, and in line with the activity in current petrorefineries, the fraction requires a hydro-isomerization upgrade. Isomerization is here performed in the presence of a Pt-loaded ZSM-5 zeolite, because oxygenates $(<1 \%$ in $\operatorname{LSR}(10 \%))$ and $\mathrm{H}_{2} \mathrm{O}\left(0.5 \times 10^{-3}\right.$ mole fraction (estimation at room temperature based on literature $\left.{ }^{41}\right)$ ) are reported to poison typical isomerization catalysts, such as $\mathrm{Pt}$ on chlorinated alumina or sulfated zirconia ${ }^{26,29,30}$. Noticeably, the equimolar ratio of hydrogen to alkane of the bio-enriched naphtha stream is in line with the operating standard conditions of isomerization units (Supplementary Note 8$)^{26}$. Despite the impurities, identical hydro-isomerization results were obtained with LSR as well as with $\operatorname{LSR}(10 \%)$, as demonstrated in the time-on-stream profiles of Fig. 5 (the difference between the circles and squares; the full composition of the LSR isomerization (ISO(10\%)) is given in Supplementary Fig. 13). The influence of individual sugar-derived oxygenates on $n$-hexane isomerization is visualized in more detail in Supplementary Figs. 14-16, which indicates that most important LPCtoN impurities, that is $\mathrm{C}_{6}$ mono-alcohols and dimethyltetrahydrofuran, have the lowest impact on isomerization deactivation. Although long-term stability may be different, there is still the practical option to remove the valuable oxygenates (and water) by distillation and use them in the gasoline blend afterwards; this will certainly further stabilize the isomerization catalysis.

A complete material carbon balance (Supplementary Figs. 17 and 18) in combination with a process-flow diagram (Supplementary Fig. 19) from the second-generation biomass via RCF, LPCtoN and a classic isomerization towards the phenolics $(85 \mathrm{~mol} \% \mathrm{C}$ of the original lignin) and a bio-enriched light naphtha isomerate (50 mol\% C of original sugars) is extensively discussed in Supplementary Note 9 and Supplementary Tables 6-8. After isomerization, the obtained stream is blended with other petrorefinery streams until, finally, gasoline is obtained. Blending levels of the isomerate can reach up to $50 \%$ (refs ${ }^{31,54}$ ), which achieves at least the target of $3 \%$ advanced biofuels from second-generation biomass. Moreover, the integration of $10 \%$ biofuels in the current transportation market seems to be feasible, certainly when LPCtoN is performed with a high cellulose loading at a water to LSR volume ratio of 87.5:12.5 (Fig. 4b, Supplementary Note 2 and Supplementary Figs. 1 and 2). Besides, there is the opportunity to combine multiple biogasoline strategies, for instance bio-ethanol with bio-based carbon-enriched LSR, which may possibly enable higher amounts than $10 \%$. 


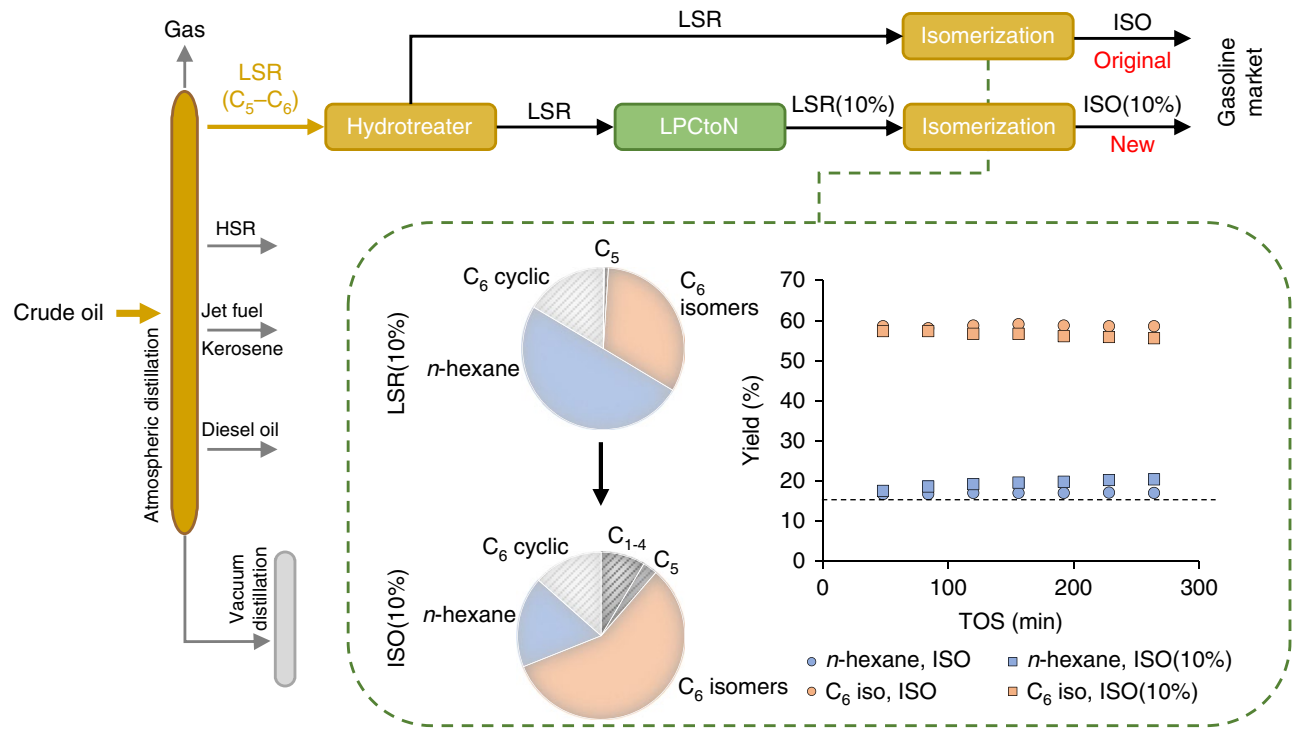

Fig. $\mathbf{5}$ | Schematic representation of the downstream integration in the isomerization unit. Hydro-isomerization of LSR and LSR(10\%). LSR(10\%) is obtained through a typical LPCtoN process with petroleum ether as the organic solvent (Fig. 2). Hydro-isomerization converts a mixture of mainly $n$-hexane into a mixture of mainly branched $\mathrm{C}_{6}$ alkanes (as in the pie charts). Moreover, hydro-isomerization of LSR(10\%) gives almost identical timeon-stream results to hydro-isomerization of original LSR (petroleum ether), shown in the graph. Conditions for hydro-isomerization: continuous-flow gas-phase quadri-reactor, $300 \mathrm{mg}$ Pt-ZSM-5 (Si/Al $=11.5$ and loading of $0.5 \mathrm{wt} \% \mathrm{Pt}$ ), total flow LSR $=1.56 \mathrm{ml} \mathrm{h}^{-1}$, total flow $\mathrm{H}_{2}=90 \mathrm{ml} \mathrm{min}^{-1}$, weight hourly space velocity $=0.84 \mathrm{~h}^{-1}$ and $T=533 \mathrm{~K}$. The dotted line represents the part of $n$-hexane in a (non-cyclic) $\mathrm{C}_{6}$-alkane mixture at thermodynamic equilibrium $(T=533 \mathrm{~K})$. ISO, isomerate.

\section{Conclusion}

This work presents the direct upstream integration of bio-derived naphtha into a classic petrorefinery. An efficient two-step conversion, starting from woody resources, is demonstrated to produce a soluble multifunctional lignin oil and a solid (hemi)cellulose pulp, a feedstock readily processed into naphtha. Central to the process design is a LPCtoN conversion, which combines two immiscible solvents (organic/water), each having their own catalyst with a specific activity (either acidic sites or redox capability). By using LSR as the organic phase in the biphasic catalytic system, it becomes enriched with mostly identical hydrocarbon molecules of renewable origin, which are identified by means of ${ }^{14} \mathrm{C}$ measurement. This allows downstream refining (hydro-isomerization and blending with gasoline) to be operated as per usual, which renders downstream separation and purification redundant, with no restrictions as to the final properties or applications. Using fossil $\mathrm{C}_{5}-\mathrm{C}_{6}$ alkanes as the organic solvent thus immediately incorporates renewable carbon into the relevant petrorefinery streams. Moreover, this route presents an elegant strategy to achieve renewability targets expressed in shortterm regulation, such as the imminent $10 \%$ bio-based carbon in $\mathrm{EU}$ biofuels (by 2020).

\section{Methods}

Synthesis of polyacid-modified $\mathrm{Ru} / \mathrm{C}$ catalyst. To obtain the polyacid-modified $\mathrm{Ru} / \mathrm{C}$, commercial ruthenium on carbon $(5 \mathrm{wt} \%)$ was modified in a $100 \mathrm{ml}$ batch reactor (Parr Instrument Co.). Ru/C (1.0g), tungstosilicic acid hydrate $(0.25 \mathrm{~g})$ and water $\left(40 \mathrm{ml}\right.$ ) were loaded into the reactor. After flushing with $\mathrm{N}_{2}$, the reactor was pressurized with a $\mathrm{H}_{2}$ pressure of $5 \mathrm{MPa}$ at room temperature. The modification was conducted with a stirring rate of 700 revolutions per minute (r.p.m.) and a temperature programme, starting at room temperature to $483 \mathrm{~K}\left( \pm 10 \mathrm{~K} \mathrm{~min}^{-1}\right)$ and kept for $1 \mathrm{~h}$ at $483 \mathrm{~K}$. Finally, the synthesized catalyst was filtered, washed with water until the $\mathrm{pH}$ of the effluent was neutral and then dried to a constant weight.

LPCtoN. Hydrodeoxygenation of Vivapur cellulose (2.0 g) or (delignified) wood sawdust (between $1.0 \mathrm{~g}$ and $3.4 \mathrm{~g}$ ) was carried out in a $100 \mathrm{ml}$ batch reactor (Parr Instrument Co.). In addition to the substrate, a biphasic system of water:alkane $(x: 40-x \mathrm{ml}$, with $x<40)$, tungstosilicic acid hydrate $(4.8 \mathrm{~g})$ and polyacid-modified $\mathrm{Ru} / \mathrm{C}(0.25 \mathrm{~g})$, was loaded into the reactor. After flushing with $\mathrm{N}_{2}$, the reactor was pressurized with a $\mathrm{H}_{2}$ pressure of $5 \mathrm{MPa}$ at room temperature. Subsequently, a stirring rate of 700 r.p.m. was installed. A temperature programme from room temperature to $423 \mathrm{~K}\left( \pm 12 \mathrm{~K} \mathrm{~min}^{-1}\right)$ and further to $493 \mathrm{~K}\left( \pm 0.5 \mathrm{~K} \mathrm{~min}^{-1}\right)$ was followed. After a reaction of $5 \mathrm{~h}$, the reactor was cooled, depressurized and opened for sampling and analysis. GC analysis of the organic liquid phase was performed on a Hewlett Packard 5890 GC equipped with an HP 7673 autosampler, a $60 \mathrm{~m}$ HP-1 column and a FID. GC analysis of the gaseous phase was performed on an Interscience Trace GC with He, equipped with Hayesep Q and RTX-1 columns with a FID and thermal conductivity detector.

RCF. A typical RCF was carried out in a $100 \mathrm{ml}$ batch reactor (Parr Instrument Co.). The reactor was loaded with birch sawdust ( $2.0 \mathrm{~g}$ Betula pendula, $0.25-0.50 \mathrm{~mm}), \mathrm{Ni}-\mathrm{Al}_{2} \mathrm{O}_{3}$ catalyst $(0.2 \mathrm{~g}, 21 \% \mathrm{Ni})$ and methanol ( $\left.40 \mathrm{ml}\right)$. After flushing with $\mathrm{N}_{2}$, the reactor was pressurized with a $\mathrm{H}_{2}$ pressure of $3 \mathrm{MPa}$ at room temperature. Subsequently, a stirring rate of 750 r.p.m. was installed. A temperature programme from room temperature to $523 \mathrm{~K}\left( \pm 10 \mathrm{~K} \mathrm{~min}^{-1}\right)$ and kept for $3 \mathrm{~h}$ at $523 \mathrm{~K}$ was followed. After the reaction, extraction with different solvents and filtration gave a lignin oil and carbohydrate pulp. Both streams were analysed and the carbohydrate pulp was further converted in the LPCtoN process.

Hydro-isomerization. The catalytic hydro-isomerization of bio-based carbonenriched (10\%) LSR was carried out in a downstream continuous-flow quadrireactor that contained four parallel alloy 600 reactor tubes of $3 \mathrm{~mm}$ internal diameter. The reactor was loaded with $300 \mathrm{mg}$ of Pt-ZSM- 5 catalyst $(\mathrm{Si} / \mathrm{Al}=11.5$, loading of $0.5 \mathrm{wt} \% \mathrm{Pt}, 0.25-0.5 \mathrm{~mm}$ fraction) and placed in the middle part of the reactor between quartz to limit the contact time. The catalyst was synthesized via incipient wetness impregnation with tetraamineplatinum(II) chloride monohydrate and activated before reaction in three steps: (1) oxidation with an $\mathrm{O}_{2}$ flow $\left(20 \mathrm{ml} \mathrm{min}^{-1}\right.$ per reactor) at $623 \mathrm{~K}$ for $2 \mathrm{~h}$, (2) flushing with a $\mathrm{N}_{2}$ flow $\left(20 \mathrm{ml} \mathrm{min}^{-1}\right.$ per reactor) at $673 \mathrm{~K}$ for $15 \mathrm{~min}$ and (3) reduction with a $\mathrm{H}_{2}$ flow $\left(20 \mathrm{ml} \mathrm{min}^{-1}\right.$ per reactor) at $673 \mathrm{~K}$ for $2 \mathrm{~h}$. LSR was introduced into the system using a Perfusor Space pump (Braun) at a rate of $1.56 \mathrm{mlh}^{-1}$ (total flow) and diluted with $\mathrm{H}_{2}$ as the carrier gas (total flow $=90 \mathrm{ml} \mathrm{min}^{-1}$ ), which corresponds to a weight hourly space velocity of $0.84 \mathrm{~h}^{-1}$. The reaction was conducted at $533 \mathrm{~K}$ and atmospheric pressure. Products were analysed with an online GC (CP-Poraplot Q-HT column) with FID.

SEM. Images were recorded by using a JEOL JSM-6010 JV microscope after coating the samples with gold using a JEOL JSC-1300 sputter.

NMR spectroscopy. In addition to GC, analysis of the organic phase after LPCtoN reaction was carried out by ${ }^{1} \mathrm{H}$ NMR and $\mathrm{H}$-decoupled ${ }^{13} \mathrm{C}$ NMR spectroscopy on a Bruker Avance $400 \mathrm{MHz}$ spectrometer. Chloroform- $d$ was used as the NMR solvent.

${ }^{14} \mathrm{C}$ determination. Samples (1.0-1.5 g) were mixed with $12 \mathrm{ml}$ of 2,5-diphenyloxazole $\left(4 \mathrm{gl}^{-1}\right)$ and dimethyl 1,4-bis-2-(4-methyl-5-phenyloxazoly) 
benzene $\left.\left(0.35 \mathrm{gl}^{-1}\right)\right)$ dissolved in a toluene scintillation cocktail. Their radiocarbon content was determined on a Tri-Carb 4810 TR LSC at the $0-156 \mathrm{keV}$ count region with a $300 \mathrm{~min}$ count time. For the calculation of the biomass carbon content, a ${ }^{14} \mathrm{C}$ content of 13.56/0.93 disintegrations per minute per gram $\mathrm{C}$ was regarded as the $100 \%$ biomass carbon content.

\section{Data availability}

Supplementary Information gives additional and supporting data. Further data that support the plots within this paper and other findings of this study are available from the corresponding author upon reasonable request.

Received: 29 March 2018; Accepted: 16 August 2018; Published online: 24 September 2018

\section{References}

1. Huber, G. W., Iborra, S. \& Corma, A. Synthesis of transportation fuels from biomass: chemistry, catalysts, and engineering. Chem. Rev. 106, 4044-4098 (2006).

2. Climent, M. J., Corma, A. \& Iborra, S. Conversion of biomass platform molecules into fuel additives and liquid hydrocarbon fuels. Green Chem. 16 516-547 (2014).

3. Wang, G. H. et al. Nitrogen-doped ordered mesoporous carbon supported bimetallic PtCo nanoparticles for upgrading of biophenolics. Angew. Chem. Int. Ed. 55, 8850-8855 (2016).

4. Corma, A., Iborra, S. \& Velty, A. Chemical routes for the transformation of biomass into chemicals. Chem. Rev. 107, 2411-2502 (2007).

5. Rinaldi, R. et al. Paving the way for lignin valorisation: recent advances in bioengineering, biorefining and catalysis. Angew. Chem. Int. Ed. 55, 8164-8215 (2016).

6. Schutyser, W. et al. Chemicals from lignin: an interplay of lignocellulose fractionation, depolymerisation, and upgrading. Chem. Soc. Rev. 47 852-908 (2018).

7. Dusselier, M., Mascal, M. \& Sels, B. in Selective Catalysis for Renewable Feedstocks and Chemicals (ed. Nicholas, K. M.) 1-40 (Springer International Publishing, Heidelberg, 2014).

8. Deneyer, A. et al. Alkane production from biomass: chemo-, bioand integrated catalytic approaches. Curr. Opin. Chem. Biol. 29, 40-48 (2015).

9. Alonso, D. M., Bond, J. Q. \& Dumesic, J. A. Catalytic conversion of biomass to biofuels. Green Chem. 12, 1493-1513 (2010).

10. Nguyen, Q. et al. Global Production of Second Generation Biofuels: Trends and Influences (Dovetail Partners Inc., Minneapolis, 2017).

11. Melton, N., Axsen, J. \& Sperling, D. Moving beyond alternative fuel hype to decarbonize transportation. Nat. Energy 1, 16013 (2016).

12. The European Parliament and the Council of the European Union Directive 2009/28/EC of the European Parliament and of the Council of 23 April 2009 on the Promotion of the Use of Energy from Renewable Sources and Amending and Subsequently Repealing Directives 2001/77/EC and 2003/30/EC (European Union, 2009)

13. Sarrazin, P., Colin, B. \& Martino, G. in Handbook of Heterogeneous Catalysis (eds Ertl, G., Knözinger, H., Schüth, F. \& Weitkamp, J.) Part 13.1 (WileyVCH, Weinheim, 2008).

14. Román-Leshkov, Y., Barrett, C. J., Liu, Z. Y. \& Dumesic, J. A. Production of dimethylfuran for liquid fuels from biomass-derived carbohydrates. Nature 447, 982-985 (2007).

15. Jenkins, R. W. et al. The effect of functional groups in bio-derived fuel candidates. ChemSusChem 9, 922-931 (2016).

16. Molino, A., Chianese, S. \& Musmarra, D. Biomass gasification technology: the state of the art overview. J. Energy Chem. 25, 10-25 (2016).

17. Baliban, R. C. et al. Hardwood biomass to gasoline, diesel, and jet fuel: 1 . Process synthesis and global optimization of a thermochemical refinery. Energy Fuels 27, 4302-4324 (2013).

18. Venkatakrishnan, V. K., Delgass, W. N., Ribeiro, F. H. \& Agrawal, R. Oxygen removal from intact biomass to produce liquid fuel range hydrocarbons via fast-hydropyrolysis and vapor-phase catalytic hydrodeoxygenation. Green Chem. 17, 178-183 (2015).

19. Kan, T., Strezov, V. \& Evans, T. J. Lignocellulosic biomass pyrolysis: a review of product properties and effects of pyrolysis parameters. Renew. Sustain. Energy Rev. 57, 126-1140 (2016).

20. Lange, J.-P. Lignocellulose liquefaction to biocrude-a tutorial review. ChemSusChem 11, 997-1014 (2018).

21. Jahangiri, H., Bennett, J., Mahjoubi, P., Wilson, K. \& Gu, S. A review of advanced catalyst development for Fischer-Tropsch synthesis of hydrocarbons from biomass derived syn-gas. Catal. Sci. Technol. 4, 2210-2229 (2014)

22. Liu, S., Tamura, M., Nakagawa, Y. \& Tomishige, K. One-pot conversion of cellulose into $n$-hexane over the $\mathrm{Ir}-\mathrm{ReO}_{x} / \mathrm{SiO}_{2}$ catalyst combined with HZSM-5. ACS Sustain. Chem. Eng. 2, 1819-1827 (2014).
23. Op de Beeck, B. et al. Direct catalytic conversion of cellulose to liquid straight-chain alkanes. Energy Environ. Sci. 8, 230-240 (2015).

24. Liu, S. et al. Selective transformation of hemicellulose (xylan) into $n$-pentane, pentanols or xylitol over $\mathrm{Ir}-\mathrm{ReO}_{x} / \mathrm{SiO}_{2}$ catalyst combined with acids. Green Chem. 18, 165-175 (2016).

25. Xia, Q. et al. Direct hydrodeoxygenation of raw woody biomass into liquid alkanes. Nat. Commun. 7, 11162 (2016).

26. Valavarasu, G. \& Sairam, B. Light naphtha isomerization process: a review. Pet. Sci. Technol. 31, 580-592 (2013).

27. Liu, Y. et al. One-pot catalytic conversion of raw lignocellulosic biomass into gasoline alkanes and chemicals over $\mathrm{LiTaMoO}_{6}$ and $\mathrm{Ru} / \mathrm{C}$ in aqueous phosphoric acid. ACS Sustain. Chem. Eng. 3, 1745-1755 (2015)

28. Schwartz, T. J. et al. Engineering catalyst microenvironments for metalcatalyzed hydrogenation of biologically derived platform chemicals. Angew. Chem. Int. Ed. 53, 12718-12722 (2014).

29. Swan, T. S. in Handbook of Heterogeneous Catalysis (eds. Ertl, G., Knözinger, H., Schüth, F. \& Weitkamp, J.) Part 13.7 (Wiley-VCH, Weinheim, 2008).

30. Jechura, J. Gasoline Upgrading: Reforming, Isomerization, \& Alkylation (Colorado School of Mines, 2017).

31. Jechura, J. Refinery Feedstocks \& Products: Properties \& Specifications (Colorado School of Mines, 2017).

32. Kozhevnikov, I. V. Catalysis by heteropoly acids and multicomponent polyoxometalates in liquid-phase reactions. Chem. Rev. 98, 171-198 (1998).

33. Timofeeva, M. N. Acid catalysis by heteropoly acids. Appl. Catal. A 256, 19-35 (2003).

34. Mohd Azhar, S. H. et al. Yeasts in sustainable bioethanol production: a review. Biochem. Biophys. Rep. 10, 52-61 (2017).

35. Hatch, L. F. \& Matar, S. From Hydrocarbons to Petrochemicals (Gulf Publishing Co, Houston, 1981).

36. Izumi, Y., Hasebe, R. \& Urabe, K. Catalysis by heterogeneous supported heteropoly acid. J. Catal. 84, 402-409 (1983).

37. Román-Leshkov, Y., Chheda, J. N. \& Dumesic, J. A. Phase modifiers promote efficient production of hydroxymethylfurfural from fructose. Science 312, 1933-1937 (2006)

38. Román-Leshkov, Y. \& Dumesic, J. A. Solvent effects on fructose dehydration to 5-hydroxymethylfurfural in biphasic systems saturated with inorganic salts. Top. Catal. 52, 297-303 (2009).

39. Saha, B. \& Abu-Omar, M. M. Advances in 5-hydroxymethylfurfural production from biomass in biphasic solvents. Green Chem. 16, 24-38 (2014).

40. Schatzberg, P. Solubilities of water in several normal alkanes from C7 to C16. J. Phys. Chem. 67, 776-779 (1963)

41. Tsonopoulos, C. \& Wilson, G. M. High-temperature mutual solubilities of hydrocarbons and water. Part I: Benzene, cyclohexane and $n$-hexane. AIChE J. 29, 990-999 (1983).

42. Heidman, J. L., Tsonopoulos, C., Brady, C. J. \& Wilson, G. M. Hightemperature mutual solubilities of hydrocarbons and water. Part II: Ethylbenzene, ethylcyclohexane, and $n$-octane. AIChE J. 31, 376-384 (1985)

43. Tsonopoulos, C. Thermodynamic analysis of the mutual solubilities of hydrocarbons and water. Fluid Phase Equilib. 156, 21-33 (1999).

44. Galkin, M. V. \& Samec, J. S. M. Lignin valorization through catalytic lignocellulose fractionation: a fundamental platform for the future biorefinery. ChemSusChem 9, 1544-1558 (2016).

45. Garrett, M. D., Bennett, S. C., Hardacre, C., Patrick, R. \& Sheldrake, G. N. New methods in biomass depolymerisation: catalytic hydrogenolysis of barks. RSC Adv. 3, 21552-21557 (2013).

46. Renders, T., Van den Bosch, S., Koelewijn, S.-F., Schutyser, W. \& Sels, B.F. Lignin-first biomass fractionation: the advent of active stabilisation strategies. Energy Environ. Sci. 10, 1551-1557 (2017).

47. Van den Bosch, S. et al. Reductive lignocellulose fractionation into soluble lignin-derived phenolic mono- and dimers and processable carbohydrate pulp. Energy Environ. Sci. 8, 1748-1763 (2015).

48. Shuai, L. et al. Formaldehyde stabilization facilitates lignin monomer production during biomass depolymerization. Science 354, 329-333 (2016)

49. Van den Bosch, S. et al. Integrating lignin valorization and bio-ethanol production: on the role of $\mathrm{Ni}-\mathrm{Al}_{2} \mathrm{O}_{3}$ catalyst pellets during lignin-first fractionation. Green Chem. 19, 3313-3326 (2017).

50. Deneyer, A. et al. Compositional and structural feedstock requirements of a liquid phase cellulose-to-naphtha process in a carbon- and hydrogen-neutral biorefinery context. Green Chem. 18, 5594-5606 (2016).

51. Verboekend, D., Liao, Y., Schutyser, W. \& Sels, B. F. Alkylphenols to phenol and olefins by zeolite catalysis: a pathway to valorize raw and fossilized lignocellulose. Green Chem. 18, 297-306 (2015).

52. Koelewijn, S.-F. et al. Sustainable bisphenols from renewable softwood lignin feedstock for polycarbonates and cyanate ester resins. Green Chem. 19, 2561-2570 (2017). 
53. Koelewijn, S.-F. et al. Promising bulk production of a potentially benign bisphenol. A replacement from a hardwood lignin platform. Green Chem. 20, 1050-1058 (2018).

54. Pasadakis, N., Gaganis, V. \& Foteinopoulos, C. Octane number prediction for gasoline blends. Fuel Process. Technol. 87, 505-509 (2006).

\section{Acknowledgements}

This work was performed in the framework of the IWT-SBO project ARBOREF. A.D. acknowledges the Agency for Innovation by Science and Technology (IWT) for a PhD grant. E.P. and T.R. acknowledge Research Foundation-Flanders (FWO) for financial support. S.V.d.B. and T.E. acknowledge KU Leuven for a BOF-PDM grant. M.D. acknowledges FWO and BOFZAP. B. Op de Beeck is thanked for the initial exploratory work.

\section{Author contributions}

M.D., B.F.S. and A.D. conceived the LPCtoN integration. Most experimental work (catalyst preparation, SEM, LPCtoN reactions and GC analysis) was performed by A.D., assisted by E.P. Experimental work with the RCF was performed by T.R. and S.V.d.B The hydro-isomerization experimental work was performed by A.D and T.E., assisted by N.V.O. The ${ }^{14} \mathrm{C}$ determination was performed by T.S. and T.I.K. Data analysis and writing was done by A.D. supported with the critical input of M.D. and B.F.S.

\section{Competing interests}

M.D. and B.F.S. have a pending patent (WO2015172208A1) on the LPCtoN technology. The other authors declare no competing interests.

\section{Additional information}

Supplementary information is available for this paper at https://doi.org/10.1038/ s41560-018-0245-6.

Reprints and permissions information is available at www.nature.com/reprints. Correspondence and requests for materials should be addressed to M.D. or B.F.S. Publisher's note: Springer Nature remains neutral with regard to jurisdictional claims in published maps and institutional affiliations. 